\title{
Introduction
}

\section{THE SUCCESS OF NATURALISM}

Without doubt naturalism has been successful in shaping the philosophical landscape like no other philosophical tradition in the second half of the last century. For sure this is the case within analytic philosophy. Jaegwon Kim states it straightforwardly:

If current philosophy can be said to have a philosophical ideology, it is, unquestionably, naturalism. Philosophical naturalism has guided and constrained analytic philosophy as its reigning creed from much of the twentieth century. (Kim 2003, 84)

David Papineau goes even a step further than Kim by claiming that most contemporary philosophers are not simply naturalists as a matter of fact but

(...) nearly everybody nowadays wants to be a 'naturalist' (...). (Papineau 1993,

1 , my italics)

Naturalism is not only the most accepted creed among analytic philosophers but a wide-spread world-view throughout contemporary intellectual culture.

What is so special about naturalism that it became so popular in our times? Does naturalism owe its popularity merely to an intellectual fashion than to any serious argument? Is it chic to be a naturalist? What other reasons than fashion could be there that it took so long for intellectuals to appreciate naturalism?

The relatively recent provenance of naturalism and its influence among philosophical circles in particular and cultural discourse in general can be explained by the rapid development of science. From the dawn of the naturalistic enterprise, a close allegiance with science can be observed. Take, for instance, the volume Naturalism and the Human Spirit published by leading American philosophers in 1944. It can be seen as a sort of manifesto for the naturalist movement. A. E. Murphy wrote a detailed review of this volume raising the question about the distinctive philosophical position of naturalists. 
He says:

Starting from the acknowledged achievements of scientific inquiry so far, the 'naturalists' intend to show that these same methods, or others essentially 'continuous' with them, are adequate also to those aspects and dimensions of 'the human spirit' which in the past have often been held on philosophical grounds to transcend the methods and aims of science. (Murphy 1945, 405)

According to Murphy's characterization naturalism appears to be above all a methodological precept. It prescribes the scientific method as the only source for obtaining reliable knowledge. Thus, naturalism says that we should understand things by going beyond science as little as possible.

This methodological doctrine rests on an epistemological thesis which roughly can be set out as the thesis, that all knowledge we can acquire is obtainable only or foremost through the application of the scientific method. We can put it slightly different as follows: All forms of human investigation are best conducted within the framework of our empirical knowledge of the world and empirical knowledge of our world is paradigmatically gained within scientific discourse.

This epistemological thesis often comes hand in hand with an ontological thesis claiming that all that exists is what (in principle) can be studied by science. Science studies the spatio-temporal world. Most naturalists would insist that the whole world is spatio-temporal and all the entities to be found in this world are studied by science. In other words: The entities of our spatio-temporal world are the only inhabitants of reality. This rules out immaterial entities such as $\operatorname{God}(\mathrm{s})$, Cartesian souls or spirits. The methodological, epistemological, and ontological ingredients sketched so far are paradigmatic for naturalism. A fourth doctrine can be added which is etiological in nature. In terms of an event causal story it explains how all entities whatsoever have come into existence: Each entity within the spatio-temporal world owes its existence, continuity, and end to the operation of causal forces within the spatio-temporal world. We never go outside the spatio-temporal world for explaining anything which takes place within it. The empirical world which is investigated and explained paradigmatically by the sciences is intelligible in its own right. There is no need to look for any additional explanatory help from outside. Although there is no familiar definition of naturalism at hand, the commitment to an 
explanatory closure of the spatio-temporal world can be taken plausibly as a defining feature of naturalism. A consequence of the explanatory closure is that all entities reside within the spatio-temporal world as well. Thus, minimally, naturalism consists in the rejection of supernatural entities and their interactions in our world. Interactions of supernatural entities with our world would break open the explanatory closure of the spatio-temporal world and the ontological commitments coming along with it.

Naturalism was successful in pushing the philosophical discussion into a direction where appeals to theological systems or postulated entities which lay outside the empirical world are considered with great suspicion. The contributors of Naturalism and the Human Spirit aimed at approaching those dimensions of the human person in a naturalistic way which so far on philosophical grounds were thought to reside outside the domain of science. These dimensions are, for instance, consciousness, intentionality, and subjectivity. Nowadays most philosophers consider these dimensions of the human person as belonging to the empirical-or to use a more innocent term - to the natural world. As part of the natural world, these phenomena are accessible to scientific investigation. Philosophers embracing explicitly a religious worldview accept the naturalistic intuition that science plays an eminent role in the study of the human person. The Christian philosopher Nancey Murphy, for instance, happily acknowledges that

all of the human capacities once attributed to the mind or soul are now being fruitfully studied as brain processes — or, more accurately, I should say, processes involving the brain, the rest of the nervous system and other bodily systems, all interacting in a socio-cultural world. (Murphy 2006, 56)

\section{NATURALISM AND THEISM}

Does this mean that in philosophy the question of naturalism has pretty much been settled-settled in favour of naturalism? It does not. The appearance of a pro-naturalist consensus in contemporary analytic philosophy is quite misleading. It might be true that sciences' achievements are almost unanimously acknowledged. Advocates and critics of naturalism may understand the methods and successful application of science exactly in the same way. They may agree that 
philosophy cannot neglect science when it comes to the study of nature and the human person. Naturalists and non-naturalists are, however, not unanimous about the philosophical lessons which should be drawn from sciences' achievements. In turn I will focus on some of those loci of philosophical discussion where success and limits of the naturalistic enterprise can most apparently be studied.

Non-naturalists, though sympathetic to naturalist approaches for studying reality, reject the naturalistic commitment of the explanatory and ontological closure of the spatio-temporal world. Science does neither adequately explain nor tell us all what there is and what there is not: There are other realms of reality open for epistemological and ontological reflection which go beyond our empirical knowledge of reality; call it the room of reasons, the realm of the spiritual or the divine. These assumed areas provide further explanatory sources, for instance, for an adequate non-reductive account of understanding (certain forms of) religious experiences within theism. Reductionist tenets of any sort are compatible with the naturalistic program but they are incompatible with theistic views presupposing divine (inter-)action. Naturalistic accounts of religious experience may be valuable by allowing the acceptance and the use of research on the biological, psychological, and social realization of religious experience. However, without an account of divine action, religious experience will be reducible to these merely empirical realms.

There remains a deep disagreement between naturalists and theistic thinkers, although their understanding of science might be compatible. Naturalists treat religious experiences merely as natural phenomena which are adequately describable and explainable with psychological, sociological, or neuro-biological concepts. There is nothing more to add. The exponent of a theistic worldview is an opponent of such a view in the sense that a reduction of religious experiences to mere psychological and socio-cultural explanations is rejected. From a theistic point of view as sketched above for religious experiences a reference to spiritual beings or God is essential.

The particular debate about how religious experiences are adequately conceived points towards a general matter of dispute between naturalism and its theistic rivals. The matter of dispute does not so much concern the achievements of science as such but what conclusions for one's worldview 
are drawn from it. Naturalists would say that sciences do not only provide an adequate picture of reality but more pretentiously that sciences can provide the only adequate picture. Theistic philosophers would disagree. Science does deliver true knowledge of our world but science alone cannot tell us the whole story of our world. More contentiously religious philosophers could even claim that science is of secondary importance for many questions concerning reality, for instance, when it comes to an adequate understanding of the nature of human persons, ethics, or religious experience (Moreland and Rae 2000, 40-47).

To sum it up: The matter of dispute between naturalistic and theistic thinkers concerns the role of science for the understanding of reality in toto (Bunge/Mahner 2004, 222-231): Can reality be interpreted in a more coherent and comprehensible way from a naturalistic or theistic point of view? Is naturalism superior to its theistic rival because it has the authority of science behind it? Or does theism dispose of a more comprehensive explanatory power-especially if it takes sciences seriously and aims at harmonizing a scientific understanding of reality with theistic assumptions?

\section{NATURALISM AND 'NATURALIZATION'}

Though religious worldviews are major rivals of naturalism, the most pressing questions about naturalism do arise from a stance within our empirical world. The great majority of philosophers are secular and have abandoned religion for interpreting reality. Thus, discussion about the evaluation of success and limits of naturalism mostly takes place from a stance within our empirical world.

A major battlefield of contemporary discussion concerns the question how such philosophical key notions as 'self', 'subjectivity', 'first person perspective', 'moral values', 'content', and 'free will' can be accommodated in a naturalistic outlook of reality. Traditionally, these phenomena were understood as residing outside the world accessible to science. Thus, a serious use of these notions requires, according to naturalism, 'naturalization'. That is, these controversial notions are to be defined from uncontroversial notions of the established sciences. Take, for instance, the problem of the first person perspective: 'Naturalization of the 
first person perspective' would mean that our subjective first personal point of view could be reduced to brain activated information processing systems (giving rise to our impression of a first person perspective). The subjective first personal point of view is replaced then with an objective third personal one. There is, however, no agreement about what should count as 'naturalization' and according to which standards it can be achieved.

Furthermore, all the work done by naturalists so far has produced no clear indications how to naturalize the phenomena mentioned above. Francis Crick and Christof Koch state it openly that

no one has produced any plausible explanation as to how the experience of the redness of red could arise from the actions of the brain. (Crick and Koch 2003, 119)

Although Crick and Koch refer to the problem of qualia only, promising strategies to naturalize subjectivity, content, and the first person perspective in general are missing. Lynne Baker rightly called the first person perspective a test case for naturalism's success (Baker 1998). The lack of successful projects of naturalization, especially in the context of our mental life, nourishes sceptical thoughts about naturalism: Is it not a more promising strategy to treat reasons, meanings, values, or subjectivity as phenomena sui generis which can be conceived as powers human beings naturally are endowed with? As phenomena sui generis they belong to the 'room of reasons' and ought not to be reduced to something unproblematic from a scientific point of view, such as the realm of causes (McDowell 2004).

McDowell pleas for a liberal form of naturalism in which thinking, knowing and feeling are accepted as being part of our way of being animals. Any aims of naturalizing them by integrating them into the realm of causes and natural laws as the proper space of science are rejected because human beings as rational animals find no place in such a constricted scientific picture anymore. McDowell's plea for liberal naturalism can be interpreted as a sign that restrictive forms of naturalism were unsuccessful so far.

A possible strategy of defence for reductive naturalists might be to provide a modest argument for naturalization. Such an argument would 
claim that a sufficient or conclusive reason for satisfactory naturalization cannot be given (yet). What, however, can be given is some reason for thinking that the strategy to naturalize our mental life is the right way to proceed. It is the right way to proceed because all alternatives are less convincing in the light of currently available evidence. All things taken together (current empirical evidence, analysis of arguments...) give a large boost for the assumption that the only practicable strategy consists in naturalizing our mental life and the concepts connected with it (Melnyk 2003, 238-309). Such an argument does not provide a proof for naturalization; it leaves even open whether such a proof can be given. Such an argument aims at a redistribution of the burden of proof. It says that there is no liberty to pretend that naturalization of our mental life is an open question in the sense that non-naturalistic rival theories (for instance a realistic interpretation of our folk psychological concepts or dualistic theories) are equally probable in the light of contemporary scientific knowledge.

Non-naturalists, of course, would disagree with such a conclusion. First, they would claim that the burden of proof lies on the reductionists' side: They have to re-describe and re-explain the phenomena we take for granted in everyday life within a scientific third personal framework. Second, nonnaturalists would assume that a change of subject takes place. Phenomena that stimulate our philosophical interests are assimilated with the natural mechanisms which support these phenomena and make them possible.

To sum it up: The concept of 'naturalization' is a major issue of dispute in the current debate on naturalism. It might be worthwhile to study more thoroughly what criteria of success or failure for naturalization are invoked. Such a clarification would be a first step towards setting up standards according to which the status or likelihood of naturalization could be measured.

\section{REDUCTIVE AND NON-REDUCTIVE NATURALISM}

The discussion whether liberal or more restrictive forms of naturalism shall be pursued points towards another problem discussed in contemporary philosophical debate. The naturalist's paradigm for an adequate explanation of reality is science. Unfortunately it is all but clear what has 
to be considered as science. Is a naturalist only committed towards the socalled "hard sciences", physics, and biology, or does he/she have to take into account "soft sciences", such as psychology, as well? This ambiguity gives rise to a whole array of versions of naturalism which are hardly compatible with each other.

There are reductive and non-reductive naturalists. The position of reductive naturalism claims that a complete physics (probably in addition with some other well-established science such as chemistry and biology) would provide all the ontological and explanatory means for understanding reality. Within such a framework, there would not be any need to refer, for instance, to psychological categories for accounting for our mental life. Non-reductive naturalists want to preserve higher level phenomena instead, such as the mental, as a reality sui generis, which cannot be reduced to lower levels, for instance, the biological or physical one. They have offered various forms of supervenience relations and developed emergentist scenarios for providing an explanatory and ontological framework within which higher level entities find a natural home in a physical world. According to their understanding restrictive forms of naturalism are too narrow because much of what we consider to be a natural and valuable part of our world is being denied. Furthermore important tools for an adequate understanding of ourselves and our world would be missing, for instance, the causal efficacy of our mental life, responsible agency or a robust understanding of meaning and the normative.

Reductive naturalists tend to accuse their non-reductive colleagues to be rather unclear about how emergentist scenarios or supervenience relations do precisely work: Either these higher level entities are metaphysically inflated and end into some version of dualist thinking; or higher level entities are so tightly bound to their realizing subvenient base that it comes close to a full blown reduction to their physical realizers (Kim 1995). Whether or not a substantial form of physicalism can be combined with the rejection of the so-called higher level reduction is still a great matter of dispute.

In my view, this dispute reflects the need to examine more accurately the epistemological and ontological implications of a layered model or reality as presupposed by most reductive and non-reductive naturalists. As long as the (epistemological and ontological) status of the single layers of 
reality and their interrelationship is not untangled and made more precisely deadlocks of the current debates can hardly be solved (Heil 2003, 49-50).

\section{NATURALISM, COMMON SENSE, AND VALUES}

A distinction similar to reductive and non-reductive naturalists is the one between hard and soft naturalists. P. F. Strawson draws this distinction in Scepticism and Naturalism. Hard naturalism, according to Strawson, attempts to view the world in an objective and detached light from the third person perspective. For hard naturalism only natural phenomena as conceived from an impersonal scientific point of view exist. Soft naturalism, on the contrary, expands the notion of existence in such a way that it compromises notions of folk psychology and common sense. Thus, soft naturalism accepts that the world is conceived from a first personal point of view as well. Strawson argues that these two approaches to reality are compatible if they are seen as being valid relative to a certain point of view. In the case of conflict between the two views, Strawson would side with soft against hard naturalism (Strawson 1987, 107). Many naturalists would disagree with Strawson. Drees, for instance, is of the opinion that in the light of the success of science it is rational to give hard naturalism priority over soft naturalism in the case of conflict:

[...] science not only supplements, but, in many instances on good grounds, corrects, our (soft) 'natural' understanding of reality. (Drees 1996, 11)

The dispute between hard and soft naturalism points towards the question which epistemological status naturalism assigns to humanities, folk psychology, and common sense. Hard naturalism makes science the prime arbiter of truth: In the case of doubt or dispute science is to be preferred over alternative approaches to reality. Hard naturalism seems to assign full cognitive value, or objectivity, to science alone. Such a campaign arouses fears leading to another form of criticism: If science is the only avenue to a comprehensive theory of the world, then history, poetry, music, and also philosophy have not much to add. If science is in a hegemonic position to pursue objectivity, then the humanities are much farther down or-in the worst case scenario-utterly deficient in achieving objectivity. If such 
naturalistic intuitions gain credibility, on the long run, they will have a heavy impact on social life and even on therapeutic application of science itself, for instance in medicine. John Dupré discusses this point shortly on the hand of the treatment of Attention Deficit Disorder Syndrome with the drug Ritalin (Dupré 2004, 53f.). Dupré's argument is not directed against the treatment of problematic cases with psychotropic substances. What he calls attention to is the fact that such a 'scientific and reductive approach' looks natural, if not inevitable from a rational point of view. As a consequence, the success of possible alternative approaches, say a psychological analysis or the study of the child's environment, is evaluated as less promising from the beginning on. It could be argued that the disregard of such complementary or alternative approaches deprives hard naturalism from the very beginning of additional tools of explanation and/or application which might contribute to a therapy's success.

Putnam's critique of hard naturalism seems to be motivated by similar worries but in their thrust they refer to social life in general (Putnam 1990, 142-178). An epistemological demotion of the humanities, art, or common sense will encourage their depreciation. By rejecting any coherent notion of an absolute objective conception of the world Putnam finds himself in a position which is similar to the one of Strawson's soft naturalism: We are beings who cannot have a view of the world that does not reflect our interests and values. Questions about our world are always perspectivedependent. Mathematics, physics, history, art, or poetry show our conceptual choices; the world does not impose one perspective singled out from all others upon us.

What my discussion should have made clear is that hard naturalism is confronted with the reproach of 'de-humanizing' our understanding of reality. If such fundamental concepts of human existence as values, morality, freedom, and subjectivity find no a place in a world conceived from the impersonal view of science, then to be human itself is threatened. Hard naturalists have to find a response to this reproach.

This is not to downgrade the achievements of the naturalistic enterprise. The benefit of naturalism, especially of hard naturalism, was the empirical scrutiny of our common sense view and folk psychology. By asking how well our manifest image can be integrated into the scientific image naturalism draws attention to the defining features, merits, and defects of 
our common sense image of the world. Conversely, of course, the role of the scientific image has been subject of close scrutiny as well. To continue to work on these issues is a worthwhile and timely philosophical enterprise since there are no signs that science will be less successful in the years to come. Science will not loose its dominating role in shaping our understanding of reality. Thus, a thorough analysis of the consequences of sciences' achievements for our understanding of reality and its impact on cultural discourse is a significant task for philosophy. The analysis will proceed along the lines I tried to sketch: It will revolve around the explanatory power of alternative worldviews to naturalism, naturalization and reduction, the status of common sense and the humanities in a natural world and the place of values and human interests in a world conceived from the scientific point of view.

This book takes stock of the naturalist debate in recent years. Naturalists and anti-naturalists alike unfold their positions discussing success, failure, and limits of naturalistic approaches. "How successful is naturalism?" makes explicit where the lines of agreement and disagreement between naturalists and their critics are situated in contemporary philosophical discussion. A definite answer regarding naturalism's success and limits will not be found in this book. Clarity about agreement and disagreement between naturalists and non-naturalists alone would be an ample progress however.

We now turn to a summary of the articles.

\section{SUMMARY}

Gerhard Vollmer, "Can Everything be Rationally Explained Everywhere in the World?": Vollmer belongs to the most prominent German naturalists. The paper contains in a programmatic way the main theses a naturalist has to adopt according to Vollmer's understanding. Guiding principle of his understanding of naturalism is that "everything can be rationally explained everywhere in the world." For putting this principle into practice Vollmer relies on the results of natural science and critical rationalism. The scientific method shall be applied wherever we can apply it. Where we cannot apply it hypotheses must be economical in their ontological postulates and in their explanatory means. Furthermore they are to be 
criticizable. The principle of economy and of criticizability tip the balance against the assumption of entities beyond human experience: Souls, angels, or God are imaginable but dispensable for the observation, explanation and interpretation of the world.

Nancey Murphy, "Naturalism and Theism as Competing Traditions": Murphy argues that a typical understanding of the relation between naturalism and theism is that they are two nearly identical worldviews, one with and one without God. Instead, naturalism should be seen as a tradition in its own right, beginning with David Hume and Baron d'Holbach. These intellectuals treat systematically the world as a whole, humanity's place in it, immortality, religion, and the structure of society. Dawkins, Wilson, Dennett, to name a few, are current contributors to this tradition. How is one to compare large-scale traditions of this sort? Murphy draws mainly upon resources from Alasdair MacIntyre to consider what it would take to show this rather new tradition to be rationally superior to its theistic rival. She concludes that naturalism so far was unable to provide a satisfactory account of the moral 'ought' and the foundation of morality. This presents a severe crisis for the naturalist tradition which might be a small step in arguing for the theistic tradition.

Thomas Sukopp, "How Successful Is Naturalism? Talking about Achievements beyond Theism and Scientism": For Sukopp naturalism should not be confounded with "Quine's naturalistic rhetoric." Taking Quine as a paradigm of a naturalistic philosopher amounts to a man of straw in the naturalist/non-naturalist debate. Sukopp holds that naturalism should be understood as being open for scientific and other methods as long as standards of success such as explanatory power, economical use of explanatory means, and capacity of problem solving can be met. Hence a naturalist does not have to adhere dogmatically on natural sciences alone for his resources of explaining and interpreting reality. Because of this tolerance naturalism is not forced to neglect everything beyond physical objects, such as values and norms. Furthermore it is not problematic for naturalism to be modest in its explanatory aspirations: Qualia and free will have not been naturalized yet and maybe they never will. This, however, is no evidence against the success of naturalism. To be successful does not imply to be successful everywhere. 
Michael C. Rea, “How Successful Is Naturalism?”: According to Rea naturalism suffers from a substantial malady: It commits its advocates to views which are in direct tension with the attitudes, doctrines, and goals which characterize naturalism. According to Rea, naturalists are confronted with a dilemma: If naturalism is characterized as a thesis, then it falls into dissonance because adherence to a thesis is inconsistent with the naturalistic commitment to follow science where it leads. Science might overthrow the thesis which is characteristic for naturalism. This rebuke often can be found among non-naturalists. The second horn of the dilemma is more original and complex: Naturalism is committed to scientific realism and to an ontology including only things accessible to scientific investigation. But the commitment to realism forces naturalists to accept arguments that proceed by way of inference to the best explanation. In doing so, according to Rea, naturalists are forced into an ontology which cannot be investigated by science, namely substance dualism. Then, naturalism is dissonant, if the demand for explanation is rejected, and dissonant if it is accepted.

Ulrich Frey, "Naturalized Philosophy of Science: A Cognitive Approach": Ulrich Frey does not argue for naturalism in general but he gives a concrete example how a progressive naturalistic philosophy might work. His example is a naturalistic philosophy of science based on empirically accessible data about cognitive abilities of scientists. He argues that every investigation of scientific practice needs to consider the cognitive abilities of human beings, including scientists. On the basis of three case studies strong evidence is provided in support of the thesis that sciences like cognitive psychology and evolutionary biology offer good descriptions and explanations of phenomena that are of interest in the philosophy of science. So far most philosophers of science used a coarse grained approach by analyzing scientific paradigms and research programs. Many phenomena, however, are missed that way, because strengths and weaknesses of our individual thinking processes have to be considered as well. Frey's naturalistic approach does not exclude historical and sociological facts. Nor does he aim at naturalizing them. The point he makes is that it is essential for philosophy of science (and for other disciplines in philosophy as well) to rely heavily on natural sciences for methodological and epistemological purposes. 
P. M. S. Hacker, "Passing by the Naturalistic Turn: On Quine's CulDe-Sac": Quine contributed actively to the naturalistic turn away from the a priori methods of traditional philosophy to a conception of philosophy as continuous with natural science. Although there is resistance among naturalists to take Quine as a paradigm of a naturalistic philosopher (see Brandl's and Sukopp's articles), doubtlessly American naturalism is closely associated with Quine. Hacker's contribution is a thorough analysis of Quine's naturalized epistemology. According to Hacker, Quine rarely was concerned with questions of traditional epistemology. However, when he was, his answers were not part of empirically testable theories as he demanded for naturalized epistemology but traditional philosophical claims. Hacker concludes that "naturalized epistemology does not answer the great questions of epistemology and is no substitute for their answers." It remains a major task of epistemological and methodological reflection to point out conceptual confusions and incoherences of scientific theories. This does not imply that philosophy is the Queen of sciences. Rather it should be conceived as a tribunal before which scientific theories may be arraigned when trespassing beyond the limits of their qualification.

Georg Gasser \& Matthias Stefan, "The Heavy Burden of Proof for Ontological Naturalism": If one accepts scientific realism and the thesis that explanatory concepts in science imply ontological commitments, then naturalism contains an ontological program as well. The task of a naturalistic ontologist is to draw out the metaphysical implications of contemporary science. Gasser and Stefan attend to this task. First of all, it has to be made clear on which sciences a naturalistic ontologist should rely on. This, however, is all but clear. There is no generally accepted concept of science on the basis of which we can distinguish between acceptable and non-acceptable sciences. The dilemma of naturalism can be subsumed as follows: If almost everything is considered to belong to the scope of science, naturalism becomes so liberal that it runs risk of turning into triviality. If, on the contrary, naturalism becomes more restrictive it leans towards reductive physicalism or eliminativism, a price many philosophers are not willing to pay. An attractive alternative seems to be non-reductive physicalism. Referring to Jaegwon Kim's work Gasser and Stefan argue that this is no viable way either. A consequent form of naturalism seems to 
lead towards reductive or eliminative forms of physicalism. Philosophers who are unwilling to bite this bullet do better abandon naturalism.

Konrad Talmont-Kaminski, "Reason, Red in Tooth and Claw: Naturalising Enlightenment Thinking": Talmont-Kaminski's paper starts from the assumption that Enlightenment's conception of rationality became more and more a subject of cynicism in the light of the great historical calamities of the $20^{\text {th }}$ century. Enlightenment's conception of reason was logic-based. Rational solutions were considered to be universal, following necessarily from the information given and they had to conform to appropriate rules, such as logical relations. The main contribution naturalism can make is to bring light into our understanding of what it means for us humans to be rational without falling back to the Enlightenment's extreme on the one hand and the anti-intellectualism of nihilism or fundamentalism on the other. For this task any a priori qualms about reason are to be rejected. A naturalistic account to reason treats epistemic methods as open to development and situated in a specific context. Informed by Peirce's pragmatism Talmont-Kaminski's naturalistic understanding of rationality rejects the view that rational solutions are to be universally valid, rational conclusions have not to follow necessarily from prior information and the primary focus is placed upon actions not upon rules. This modest view of human reason recognizes its frailty and is naturally open for further criticism and development.

Lynne Rudder Baker, "Naturalism and the First-Person Perspective": The first-person perspective poses a challenge to naturalism. Thomas Metzinger has proposed an intriguing account of the first-person perspective that takes up that challenge-an account that draws the consequence that there are no selves, only self-models. Baker uses Metzinger's account as a case study for naturalism. For Baker the first person perspective is essential for the existence of a person. If the first person perspective is irretrievably lost, the person goes out of existence even if the person's body continues to exist. For Metzinger there are no entities in the world that are "selves" or "persons", just self-models. Selfmodels are products of information-processing systems which are phenomenal in character. We are mistaken to think that our experience of being subjects of experience points towards actual subjects of experience who we are. After a thorough analysis of Metzinger's reductionist account 
of the human self Baker works out its semantic, epistemic, and moral consequences. Finally she asks whether it would be rational and even possible to accept such a view as Metzinger exposes it.

Josef Quitterer, “Which Ontology for Naturalists?": In the contemporary discussion of philosophy of mind a major issue is the relationship of folk psychology and scientific explanations of human behaviour. Ontologically folk psychology presupposes the existence of enduring subjects which are the bearers of intentional states. Propositional attitudes presuppose acting and thinking subjects which remain the same during time. Most contemporary naturalists deny that in the world conceived from a scientific point of view there can be proper physical correlates for enduring subjects as assumed in folk psychology. The entire folk psychological system and its ontology seem to be incompatible with scientific knowledge. According to Quitterer, however, an analysis of contemporary naturalistic literature in philosophy of mind creates the impression that enduring entities are excluded from the list of possible physical correlates of mental phenomena not so much on scientific grounds but because of a one-sided preference of event ontological accounts. This preference leads to the exclusion of "endurers" from a scientific approach to the human person. Quitterer shows that there are scientific findings about human consciousness and experience which can be interpreted more adequately from the point of view of an ontology of continuants. He concludes that an adequate understanding of the human person needs both-events and continuants. Hence, there are ways to reconcile folk psychological assumptions with current scientific knowledge.

Johannes L. Brandl, "The Unmysteriousness of Consciousness: A Case Study in Naturalistic Philosophy": A naturalistic philosophy of mind is generally associated with physicalist theories. Brandl rejects this link between naturalistic philosophy and physicalistic conclusions drawn out of it. Naturalists are not to be confounded with physicalists. To make this point he uses the problem of consciousness as a case study. Brandl thinks a promising way out of the problematic anti-mentalistic stance many philosophers took after Quine is to return to ontological neutrality as promoted by members of the Vienna Circle. This makes room for what he calls a modest form of naturalism. Such a naturalism is pluralistic from an epistemological and methodological point of view. Everything which can 
be explained rationally belongs to the realm of such a modest naturalism. In this sense also consciousness is a natural property: There are reasonable explanations how living creatures come to have conscious experiences. This claim can plausibly be defended against the view that consciousness is mysterious and thus, something non-natural as long as ontology is left out of the game. The problem of qualia in a physical world, mental causation, and the mind-body-problem are simply not part of a modest naturalism's program.

Helmut Fink, „Indeterminacy of a Free Choice: Ontic, Epistemic, or Logical?": Fink aims at reconstructing the concept of free will within a naturalistic outlook of reality, that is the doctrine that neural processes like all other processes in nature obey to the laws of physics. He considers three features to be salient for the concept of free will: intelligibility, authorship, and alternative possibilities. Fink argues for a clear distinction between different modes of description on the epistemological level: "Mind talk" is not to be confounded with "matter talk." In addition to modes of description there are also different levels of description: One can either stick to the most elementary building blocks of an entity to be described, or introduce concepts at a more complex level, such as persons. A conceptual reconstruction of "free will" calls for introducing a mental mode and a personal level of description. The bulk of Fink's paper concerns the analysis of various notions of indeterminacy and their importance for the debate of alternative possibilities as presupposition of free will. From a first-person perspective thinking in alternatives is constitutive for a free choice. Fink discusses ontic, epistemic and logical indeterminacy. Fink concludes that it is only epistemic indeterminacy from a first-person perspective, even if restricted to periods of deliberation, which ultimately saves the intuition of alternate possibilities.

Löffler Winfried, "What Naturalists always Knew about Freedom: A Case Study in Narrative Sources of 'Scientific Facts'”: In recent years the philosophical landscape in Germany was dominated by one major public debate: the freedom of the will. Well-known brain scientists and empirical psychologists collected ample empirical material that they consider to be strong evidence for determinism. In his article Löffler studies accurately the history of the alleged research and how authors make use of the supposedly abundant empirical material. The conclusion of this study is 
rather perplexing: The seemingly robust empirical claims, as they are boasted by dominating scientists of the debate, are flatly wrong. Löffler even speaks of a "piece of neuromythology" which has been created over the years by a mixture of sloppy citations, confidence to hearsay, overinterpretations, slight mistranslations, confabulations, and commingling of probabilistic and strict correlations. Of course, this study is not a refutation of naturalistic accounts of free will. It does not show that we will never be able to solve the problem of free will with the help of empirical investigations. But Löffler's contribution shows that we do good to prove how modern naturalists come to the conclusion that old philosophical puzzles have been solved thanks to modern science.

\section{REFERENCES}

Baker, R. L. 1998: The First-Person Perspective: A Test for Naturalism. American Philosophical Quarterly 35, 327-348.

Bunge, M. and Mahner, M. 2004: Über die Natur der Dinge. Stuttgart: Hirzel.

Crick, F. and Koch, C. 2003: A framework for consciousness. Nature Neuroscience, 6 (2), 119-126.

Drees, W. B. 1996: Religion, Science and Naturalism. Cambridge: Cambridge University Press.

Dupré, J. 2004: “The Miracle of Monism.” In: De Caro, M. and Macarthur, D. (eds.) Naturalism in Question. Cambridge, MA: Harvard University Press, 36-58.

Heil, J. 2003: From an Ontological Point of View. Oxford: Oxford University Press.

Kim, J. 1995: "The Myth of Nonreductive Materialism.” In: Moser, Paul K. and Trout J.D. (eds.) Contemporary Materialism. New York: Routledge, 133-149.

Kim, J. 2003: The American Origins of Philosophical Naturalism. In: Audi, R. (ed.) Philosophy in America at the Turn of the Century. Journal of Philosophical Research, APA Centennial Supplement, 83-98.

McDowell, D. 2004: Naturalism and the Philosophy of Mind. In: De Caro, M. and Macarthur, D. (eds.) Naturalism in Question. Cambridge, MA: Harvard University Press, 91-105. 
Melnyk, A. 2003: A Physicalist Manifesto. Thoroughly Modern Materialism. Cambridge: Cambridge University Press.

Moreland, J. P. and Rae, S. 2000: Body and Soul. Human Nature \& the Crisis in Ethics. Downers Grove, IL: InterVarsity Press.

Murphy, A. E. 1945: Review of Naturalism and the Human Spirit. Journal of Philosophy 42, 400-417.

Murphy, N. 2006: Bodies and Souls, or Spirited Bodies? Cambridge: Cambridge University Press.

Papineau, D. 1993: Philosophical Naturalism. Oxford: Blackwell.

Putnam, H. 1990: "The Place of Facts in a World of Values." In: Putnam, H. edited by Conant, J.: Realism with a Human Face. Cambridge, MA: Harvard University Press, 142-162.

Putnam, H. 1990: "Objectivity and the Science/Ethics Distinction." In: Putnam, H. edited by Conant, J.: Realism with a Human Face. Cambridge, MA: Harvard University Press, 163-178.

Strawson, P.F. 1987: Skeptizismus und Naturalismus. Frankfurt am Main: Athenäum Verlag. 
